\title{
New Four-Die Forging Devices (FDFD) Design Solutions and Open-Die Forging Technologies
}

\author{
Viktor Lazorkin $^{1}$, Dmitriy Lazorkin ${ }^{1}$, Sergey Kuralekh ${ }^{2}$ \\ ${ }^{1}$ Lazorkin-Engineering Limited Liability Company, Zaporozhye, Ukraine \\ ${ }^{2}$ Lazorkin-Engineering Limited Liability Company, Berlin, Germany
}

Email address:

lazorkin.engineering@gmail.com (V.Lazorkin), d.lazorkin@yandex.ua (D. Lazorkin), sergey.kuralekh@yahoo.com (S. Kuralekh)

To cite this article:

Viktor Lazorkin, Dmitriy Lazorkin, Sergey Kuralekh. New Four-Die Forging Devices (FDFD) Design Solutions and Open-Die Forging Technologies. Advances in Materials. Vol. 7, No. 1, 2018, pp. 1-8. doi: 10.11648/j.am.20180701.11

Received: August 18, 2017; Accepted: November 27, 2017; Published: February 6, 2018

\begin{abstract}
Employment of four-die forging devices (FDFD) under various industrial environment on a variety of hydraulic presses differing in terms of design features and automation degree proved that in every particular case and with a view to particular production needs an individual approach is required to select both the proper FDFD design and the proper forging technology. Presented in this paper are various design solutions of FDFDs and various forging technologies based on employment of these specialized devices. The main selection criteria for proper device design and forging technology are: high production output, which should be significantly higher as compared to existing production technology output; improved metal quality and quality of products (in terms of dimensional accuracy and surface quality); cutback of the whole production cycle extent due to reduction of forging cycle, heating period and auxiliary operations duration, and higher good metal yield. The paper illustrates new FDFD design solutions and new technologies which meet these criteria for solving various technological tasks, and it also shows what changes to technological process can be eventually required to gain the maximum benefit from using the FDFD.
\end{abstract}

Keywords: Four-Die Forging, Forging Press, Ingot, Technology, Design of Devices

\section{Introduction}

Ongoing technology development, introduction of new machines, production processes and technologies is inextricably bound with development of new metal materials with quite special, sometimes unique properties. At the same time, production volumes of many commonly used and wellproven metals and alloys are not reducing and sometimes even increasing globally, especially when it appears possible to significantly improve their servicing properties. It is mostly applicable to metals and special alloys which are produced mainly by means of forging methods. In view of the large variety of materials and requirements applied to them, more new diverse technologies were recently developed to forge materials in FDFDs installed on hydraulic presses. Hydraulic forging presses are globally produced in a relatively small quantity by specialized machine-building companies. However, due to a commonly very long service life of forging presses, hundreds and hundreds of forging presses are being now employed in the industry. According to the publicly available information, more than 160 forging presses are used now in the EU countries alone. These presses from different producers and with different manufacturing dates differ also in their structure, their mechanization and automation degree and their wear condition. So at the stage of a FDFD project development all these differences shall be strictly considered, since they are of crucial importance for selection of a design solution and a forging technology to suit particular customer needs.

\section{Four-Die Forging Technologies}

Development of forging technology starts with a detailed study of a customer's existing forging technology, or, in case of a new production startup, with a development of technical requirements for new production. Prior to a forging technology development, an optimized general forging production sequence shall be developed, including ingots heating, roughand finish forging cycles performed on forging presses, re- 
heating cycles, cut-off or sawing operations, straightening jobs (if necessary) and heat treatment. The main element in this sequence is the technology of four-die forging in a FDFD. Sometimes upon results of this study customers come to a decision to change all their existing production sequence, for example: changing dimensions and shapes of initial ingots, changing ingots heating and forging technology, introducing different types of machines to cut forged products and even considerable upgrading of their existing forging presses.

FEM-based calculations proved that by means of forging operations performed in FDFD it is possible to reach a several times higher deformation ratio at each single pass as compared to conventional forging between two dies. With this forging method a workpiece does not tend to crush under the forging load applied, and there appear no cracks on it. Due to a specially developed dies movement schedule and reductions performed at high deformation ratios a significantly higher metal quality is achieved as compared to any other existing forging technologies. The whole technology of ingots (billets) forging in a FDFD can be conditionally divided into two steps: a rough forging step and a finish forging step.

At initial stage of FDFD forging technologies introduction with the first customers, workpiece reductions were performed according to a forging schedule without no metal spreading between the dies (Figure $1 \mathrm{a}, \mathrm{b}$ ). This forging method involves workpiece turning after each pass at $45^{\circ}$ around its long axis in the same circumferential direction so that to provide for required deformation treatment of entire workpiece surface starting from the second pass.

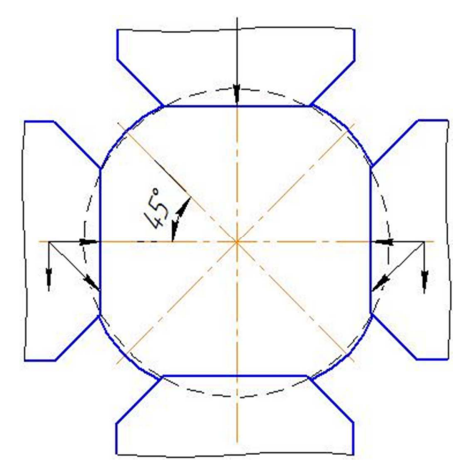

a)

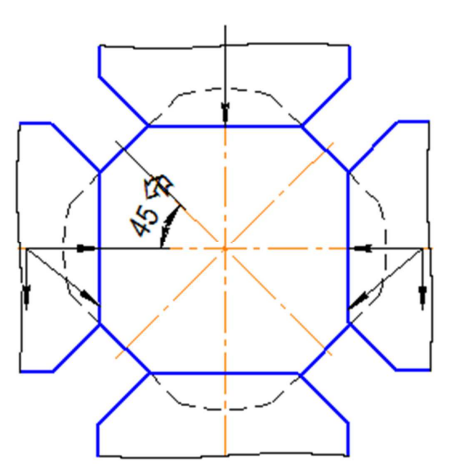

b)

Figure 1. $a, b$. Reduction schedule for a workpiece of round cross-section without metal spreading between the dies.
Further a more efficient forging schedule has been developed. It can be employed in a FDFD with higher deformation ratios (Figure $2 \mathrm{a}, \mathrm{b}$ ). This technology provides a more intensive deformation treatment of ingot cast structure due to higher single reductions and metal spreading between the dies $[1,2]$.

This forging schedule results in more intensive supplementary shear strains in the workpiece area being forged. After the workpiece is turned at $45^{\circ}$, the material spread between the dies is pressed again into the workpiece, thus inducing shear strains across the total cross-sectional area of the workpiece. Besides, all the reductions performed during every single forging pass are acting so that the cross-section of the forged part is permanently displaced in relation to

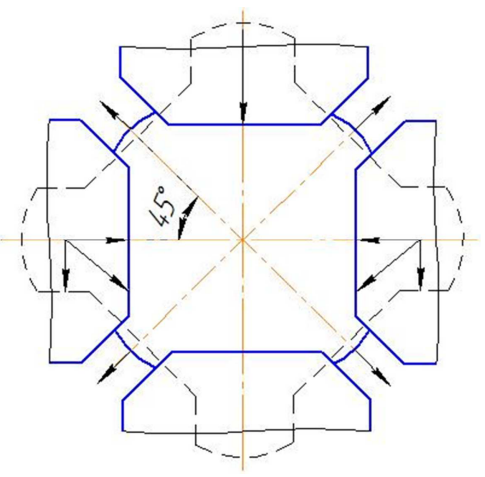

a)

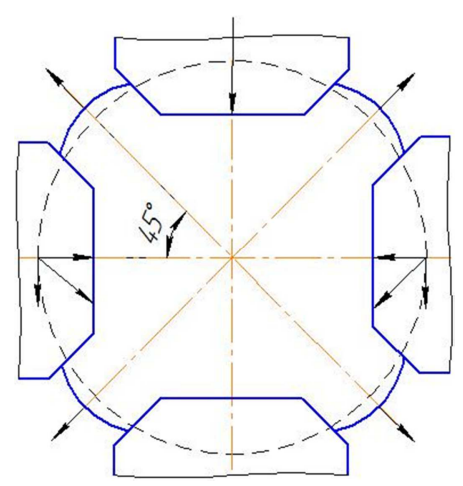

b)

Figure 2. a,b. Reduction schedule for a workpiece of round cross-section with metal spreading between the dies.

The initial workpiece cross section in one and the same circumferential direction (Figure 3) [3]. Displacement of the workpiece cross-section in circumferential direction and intensive metal volumes displacement caused by top- and lateral dies pressure induce a twisting effect to the metal structure which results in improved metal quality.

The forging schedules described above were successfully implemented in production practice on many forging presses. The authors of the paper have also developed another FDFD forging technology involvingtwisting of metal macrostructure. Upon the results of industrial trials it was found that the combination of shear strains in the material resulting from the workpiece reduction between the dies and shear strains resulting from the workpiece section-by-section 
turning performed by manipulators provides a considerable improvement of metal quality.

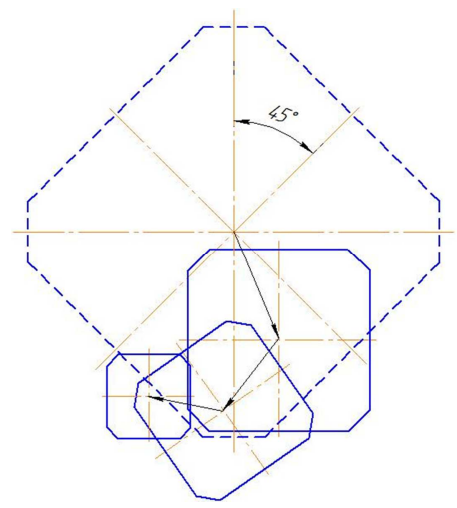

Figure 3. Reduction schedule for a workpiece of round cross-section involving intensive shear strain.

Moreover, a finer grain metal structure achieved owing to such forging treatment contributes, too, to higher metal quality. According to this method, shear forces in a workpiece are generated by means of simultaneous turning of two sections of a workpiece clamped with two manipulators gripping heads in opposite- or in one and the same directions. This technique serves to treat effectively the cast structure of metal and to obtain dense, fine-grained macrostructure of metal across the total workpiece cross-section with reduction ratios below 2:1. With the forging schedules involving supplementary shear strains it is possible to relatively easily maintain the workpiece material temperature within the required forging temperature range due to deformation heating of the area. In this case a FDFD shall preferably be employed in automatic forging machinery systems. In consideration there of, the authors have developed a special FDFD forging technology which makes it possible to maintain required metal temperature throughout the total forging cycle by means of changing the respective deformation modes. In this forging mode heat losses resulting from heat transfer from the workpiece to the forging dies and also into the ambient air are compensated by the means of changing the volume of metal being formed at deformation site at each single reduction or by means of changing the reductions frequency. This method involves permanent workpiece surface temperature control during the forging cycle and, upon results of temperature measurement, respective correction of metal volume at deformation site prior to next reduction or reductions frequency correction. This method can be employed both in manual operation mode of the press and in automatic forging cycles controlled by a computer system. Industrial trials performed on 5, 20 and $25 \mathrm{MN}$ presses proved that such forging schedules provide conditions approaching isothermal ones when forging in a FDFD. The authors have further developed new finishing technologies to be employed in FDFDs and also special finishing forging tools for this purpose. Employed for one of these technologies are forging dies with concave working surfaces so that with the dies closed a cylinder-shaped space is formed. Both rough and finish forging operations are performed with the same dies having curved concave surfaces. In this case rough forging is performed at certain deformation ratio, and the following relation is maintained:

$$
\mathrm{d}_{1} / \mathrm{d}_{2}=1,4-2,7
$$

where $d_{1}$ is an average diameter of an ingot or a billet; $\mathrm{d}_{2}$ is the diameter of circle inscribed in the space, which is formed with the dies closed.

Besides this, during finishing operation a certain relation between rough forged product diameter and diameter of finish forged product shall be maintained.

Presented in Table 1 are the examples of forged parts production by means of conventional forging technique (forging between two dies) and FDFD forging technique. Commonly used forging technology employed for the forging presses consists of two stages: first a workpiece is forged between two flat dies, then the flat dies are removed and two channel dies are mounted on the press to accomplish finish forging of a product (technology No.1). When an ingot is forged between two dies it quickly cools down to the temperature below required forging temperature range, so after the $9^{\text {th }}$ pass a workpiece reheating is required (Table 1). An ingot of $4300 \mathrm{~kg}$ is forged in 23 passes, and the total forging cycle according to conventional technology lasts 1195 seconds (excluding time loss to workpiece reheating and dies changing).

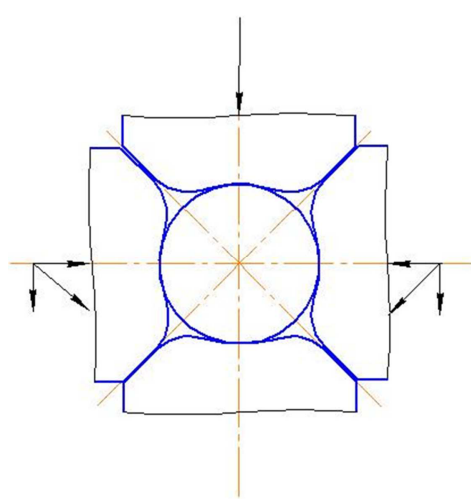

a)

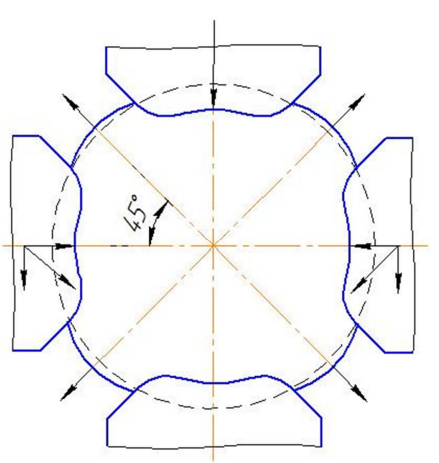

b)

Figure 4. $a$, $b$ Schedule of workpiece reduction at rough forging (a) and at finish forging (b) performed in a FDFD with the dies having concave working surfaces. 
When forging in a FDFD (technology No. 2, Table 1), 11 passes are required to forge the product, and the forging cycle duration is 587 seconds which means two-times reduction of work and time, if compared to two-dies forging technique. Moreover, with the FDFD technique no workpiece reheating is required, and no dies changing is required to perform finish forging job, since the same set of dies having concave surfaces (Figure $4 \mathrm{a}, \mathrm{b}$ ) is employed both for rough forging $\left(1^{\text {st }}\right.$ to $9^{\text {th }}$ passes $)$ and for finish forging $\left(10^{\text {th }}\right.$ and $11^{\text {th }}$ passes $)$.
Presently many forged parts producers use forging units consisting of two channel dies with springs for finishing application. For example, 15 such forging units were used to make finishing job for products in diameters from $180 \mathrm{~mm}$ to $500 \mathrm{~mm}$ at one of the companies producing alloyed steel forged parts. A FDFD with a set of dies having concave surfaces can also be successively used, but for finishing operations only.

Table 1. Examples of technologies for making forgingswith two dies (No. 1) and four dies in FDFD (No. 2).

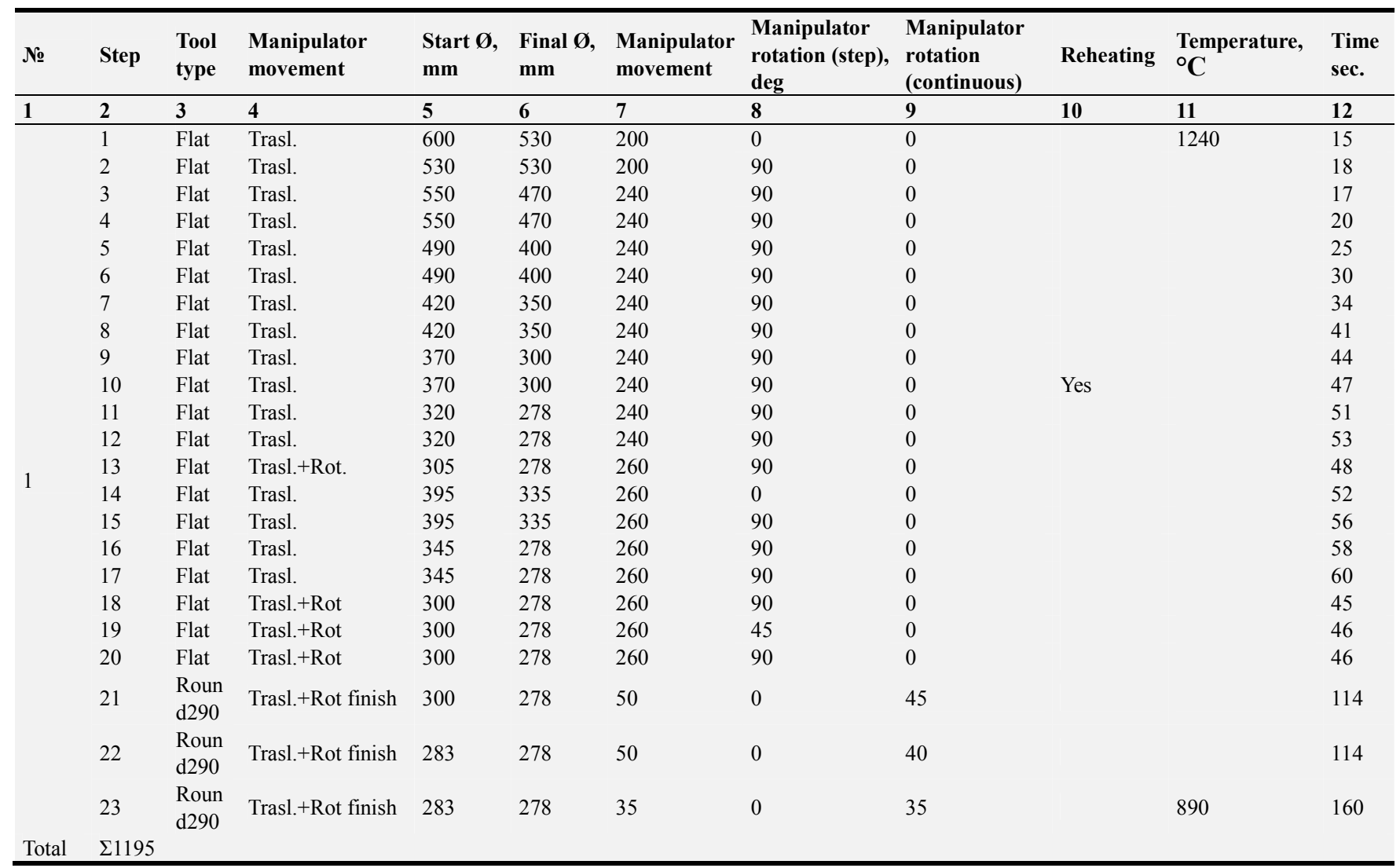

Table 1. (continued)

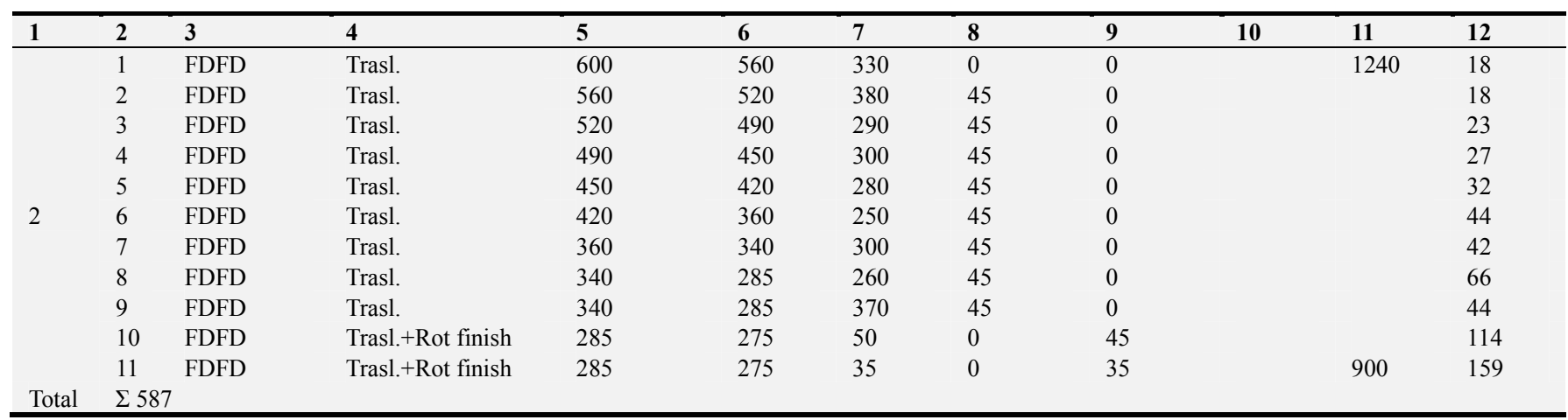

Meanwhile, such 15 sets of two-die spring-type forging units can be efficiently replaced with only one FDFD equipped with only three sets of dies designed to make finishing job for $180 \mathrm{~mm}-500 \mathrm{~mm}$ parts. A FDFD used in this case is rather a compact-size device and its price is considerably lower than that of 15 spring-type forging units consisting of two dies each.

\section{New Design Solutions of FDFDs}

The basic principle of all FDFD design solutions is: the bottom die always stays stationary, while the top body of the 
device actuated by the press top cross-beam moves down together with the top die connected thereto; the lateral dies move not only towards each other but also downwards to the bottom die thus generating supplementary shear strains.

All FDFD depending upon their design and technological features can be conditionally divided into several groups.

Groups according to technological features:

- devices intended for rough forging jobs;

- devices intended for finish forging jobs;

- devices intended for rough forging and subsequent finish forging in one and the same FDFD;

-devices intended to produce forged parts of round and square cross-section;

- devices intended to produce forged parts of round, square and flat cross-section;

- devices intended to produce forged parts of specially shaped cross-section.

Groups according to design features:

- devices equipped with die cooling systems and without die cooling systems;

- devices equipped with metal slider bearings;

- devices equipped with force feed lubrication of slider bearings;

- devices equipped with self-lubricating slider bearings;

- devices with a feature of quick connection/disconnection system to change dies in intervals between forging operations;

- devices with a quick-change system to change all four dies simultaneously;

- devices equipped with a non-rigid quick connection system intended to connect a FDFD to the press top crossbeam or to the press top die using special mechanisms incorporated into the FDFD body;

- devices equipped with supplementary guiding columns;
- devices equipped with springs intended to open the device, with no FDFD connection to the press cross-beam;

- devices equipped with rigid quick connection system to connect a FDFD to the press cross-beam;

- devices equipped with mechanisms untended to adjust the distance between opposite dies before forging operation.

Today a decision has been made to avoid using force feed lubrication systems to supply lubricant to the slider bearings and to use more advanced solutions incorporating selflubrication slider bearings which can be of different versions [4-7]. Cooling systems are used very occasionally and only in the devices intended to forge large batches of carbon- and low-alloy steel products, for example, railway axles for locomotives and carriages.

In order to ensure the quick and efficient FDFD die change, a respective FDFD design solution and special diechanging technique were developed (Figure 5) [8,9].

All four dies in such device are connected to their respective holders by means of special clamps. Also special grooves are made in the dies to receive the clamps. The clamps are designed such that they can be connected to and disconnected from the dies with the help of springs installed in the die holder holes; besides this, when disconnected from the dies, the clamps can be held either on the die holders or on the tie rods coming through the holders. When it comes to die change during a forging operation in a FDFD, the changing procedure is as follows:

First, a workpiece is removed from the device working zone. Then the dies are closed, and adjacent dies in pairs are rigidly connected with the help of U-shaped ties installed into the holes, which are made in lateral surfaces of the dies. Then the dies are disconnected from their holders and the holders are brought apart. The structure consisting of four interconnected dies rests on the bottom die.

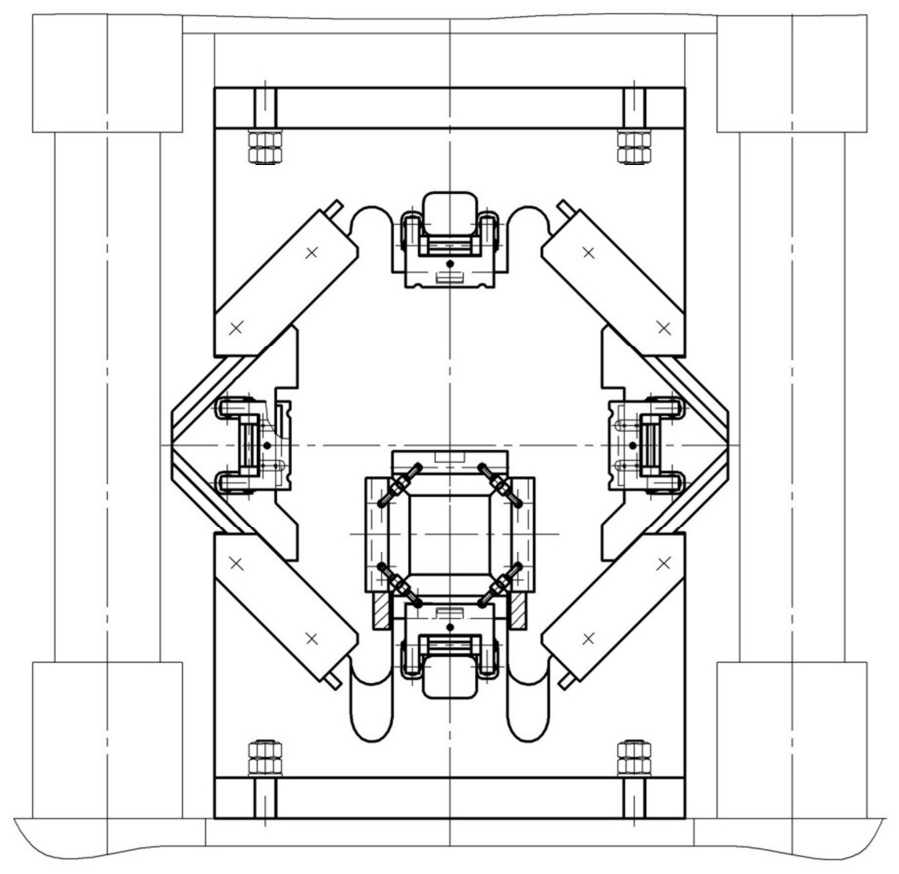

Figure 5. FDFD design solution providing for quick changing of all four dies simultaneously. 
Then this structure is gripped with a lifting attachment, for example, with a manipulator, and brought out of the device working zone to a specially provided storing place where it is put on respective support. A set of replacement dies shall be mounted in the FDFD in reverse order. It means that a set of interconnected dies is brought with the help of a manipulator on a mandrel clamped between the manipulator jaws into the device working zone. (Figure 6a).

And, finally, for the purpose of quick die change the authors of this paper have developed a die connection system employing snap-type clamps (Figure 6b). Dies mounting procedure in this case is easy like this: a complete structure consisting of four dies shall be brought into the device working zone with the help of manipulator, then the device holders are brought together by means of the press top crossbeam so that the device holders press the dies bearing surfaces. Thus the snaps get actuated to grip the dies. Thereafter the U-shaped ties shall be taken out of the holes provided in the dies and a FDFD is ready for operation.

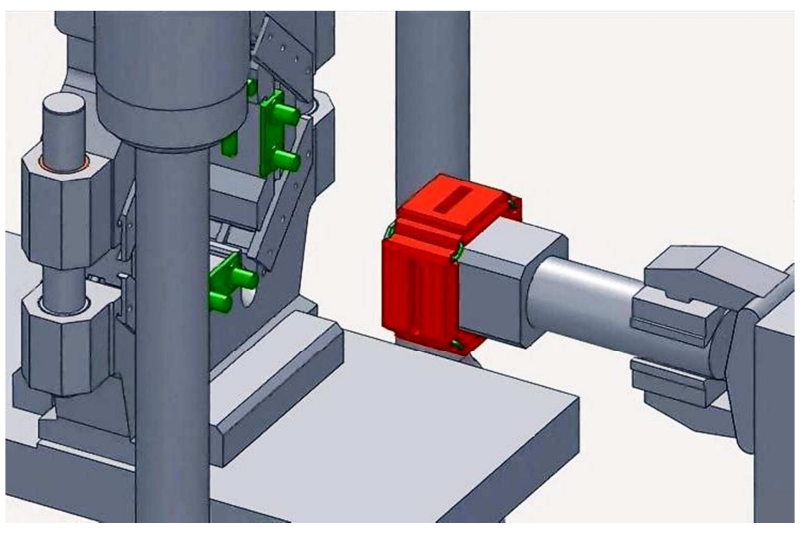

a)

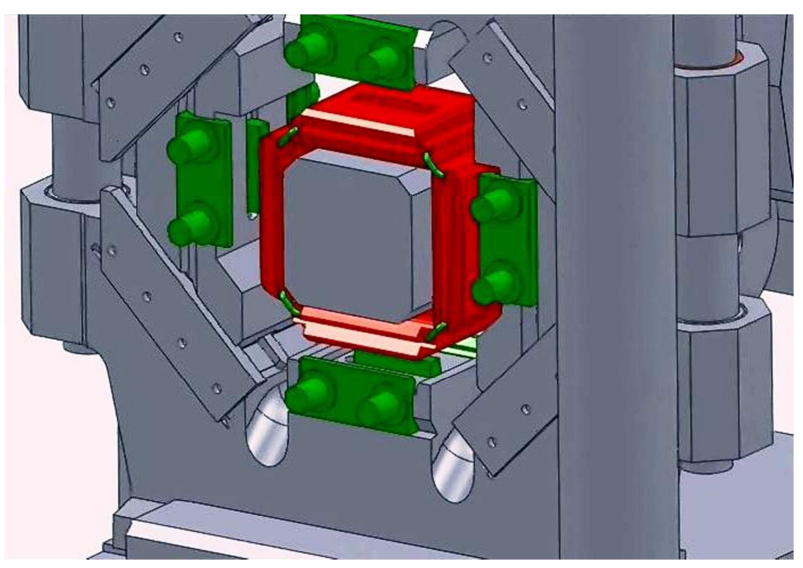

b)

Figure 6. $a, b$. Schedule of dies mounting in a FDFD.

Top- and bottom tool connection mechanisms, as well as availability of a press tool table for quick die changing are of special importance for efficient operation of FDFD. Meant here are the mechanisms used to connect the FDFD top- and bottom bodies in the forging press.

Common practice is to connect a FDFD bottom body to the working table (or tool table) of a press, while a top body is connected to the press movable cross-beam with the help of a connection fixture used for conventional existing press tool. For the application cases when maximum crosssectional size of products does not exceed $450 \mathrm{~mm}$, a FDFD design solution is used without device top body connection to the press movable cross beam. Corresponding springs are employed to bring the dies apart in this solution. FDFD equipped with springs can be much easier adapted to any existing press design and any forging technology. A device of such type can be brought into the press working zone within a few seconds and the same short time is required to take the device out from the press. Such time-saving solution is especially beneficial for applications involving forging not in a FDFD only, but sequentially between two dies, too.

However, development of a spring-type FDFD solution suitable to forge workpieces in diameters exceeding $450 \mathrm{~mm}$ is a very challenging task, since it appears rather difficult to produce adequate springs capable to move a top body with a weight exceeding 2,5 Tons to a distance exceeding $300 \mathrm{~mm}$.

In view of the said above, for the application at forging of the components with the cross-sectional size exceeding 450 $\mathrm{mm}$ a FDFD design solution has been developed. This solution includes a system of non-rigid quick connection of the device to the press cross-beam or to the top die (Figure 7). Such a FDFD has respective catches designed to quickly connect the device to the press cross-beam or to the top die and to quickly disconnect it therefrom. A mechanism used to actuate the catches is driven by an electric motor.

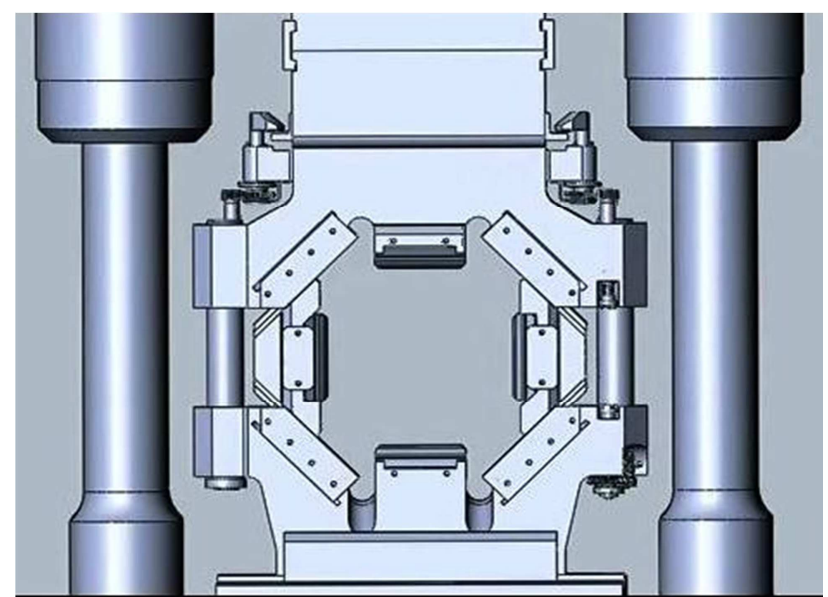

Figure 7. FDFD design solution with a system of non-rigid quick connection to the press top cross-beam.

Since the first experimental-industrial four-die forging device was built in 1990, a number of new FDFD design solutions was developed for the presses in capacities from $5 \mathrm{MN}$ to $120 \mathrm{MN}$ and for a $1,25 \mathrm{MN}$ radial forging machine; all these devices were manufactured and put into industrial operation (Table 2) [10]. These devices are employed to produce forged parts of carbon, middle-alloyed-, tool-, highalloyed- and heat-resistant steels and alloys and also nonferrous metals and alloys. 
Table 2. List of Manufacturing Plants where FDFDs are Installed.

\begin{tabular}{|c|c|c|c|c|c|c|}
\hline $\begin{array}{l}\text { Rated Press } \\
\text { Force, MN }\end{array}$ & $\begin{array}{l}\text { Year of } \\
\text { Manufacture }\end{array}$ & Company (Country) & $\begin{array}{l}\text { Qty of } \\
\text { FDFDunits }\end{array}$ & $\begin{array}{l}\text { Lubrication } \\
\text { system }\end{array}$ & $\begin{array}{l}\text { Cooling } \\
\text { system }\end{array}$ & $\begin{array}{l}\text { Self-LubricatedSliding } \\
\text { Bearings }\end{array}$ \\
\hline 1 & 2 & 3 & 4 & 5 & 6 & 7 \\
\hline 5 & 1990 & UkrNIIspetsstal (Ukraine) & 1 & No & No & No \\
\hline 1,25 (RFM) & 2000 & NPP Rubin (Ukraine) & 2 & No & No & No \\
\hline 25 & 2003 & Sidenor (Spain) & 1 & No & No & No \\
\hline 20 & 2005 & \multirow{2}{*}{$\begin{array}{l}\text { JSC Tyazhpressmash } \\
\text { (Russia) }\end{array}$} & 1 & Yes & Yes & No \\
\hline 25 & 2008 & & 1 & Yes & Yes & No \\
\hline 20 & 2006,2008 & \multirow{2}{*}{$\begin{array}{l}\text { JSC VSMPO-Avisma } \\
\text { (Russia) }\end{array}$} & 2 & No & Yes & Yes \\
\hline 25 & 2013 & & 1 & No & No & Yes \\
\hline 25 & 2006 & JSC Bummash (Russia) & 1 & Yes & Yes & No \\
\hline 20 & 2008 & SSM-Tyazhmash (Russia) & 1 & Yes & Yes & No \\
\hline 12 & 2010 & JSC ChMZ (Russia) & 1 & No & No & No \\
\hline 120 & 2010 & \multirow{2}{*}{$\begin{array}{l}\text { TongyuHeavy Industry Co., } \\
\text { Ltd.(China) }\end{array}$} & 1 & Yes & Yes & No \\
\hline 12.5 & 2013 & & 1 & Yes & Yes & No \\
\hline 16 & 2010 & Qilu SpecialSteel Co.,(China) & 1 & Yes & Yes & No \\
\hline 20,30 & 2010 & Baotou Iron \& Steel Co.,(China) & 2 & Yes & Yes & No \\
\hline 45 & 2010 & $\begin{array}{l}\text { Seri Machinery Equipment Co., Ltd } \\
\text { (China) }\end{array}$ & 1 & Yes & Yes & No \\
\hline 12 & 2011 & $\begin{array}{l}\text { Metal Manufacturing Company, } \\
\text { Zhongshan (China) }\end{array}$ & 1 & Yes & Yes & No \\
\hline 25 & 2012 & $\begin{array}{l}\text { Chongqing instrument materials } \\
\text { research institute (China) }\end{array}$ & 1 & Yes & Yes & No \\
\hline 10 & 2011 & $\begin{array}{l}\text { Kind \& Co. EdelstaHlwerk } \\
\text { (Germany) }\end{array}$ & 1 & Yes & Yes & No \\
\hline 30 & 2014 & Villares Metals S.A. (Brazil) & 1 & No & No & Yes \\
\hline 30 & 2014 & Acciaierie Valbruna S.P.A (Italy) & 1 & No & Yes & Yes \\
\hline 35 & 2017 & Ruspolymet (Russia) & 1 & Yes & Yes & No \\
\hline $15^{*}$ & 2018 & MIDHANI (India) & 1 & Yes & Yes & No \\
\hline
\end{tabular}

* - currently being manufactured

\section{Conclusions}

Due to the variety of hydraulic forging presses applied in the forging industry, selection of a forging technology and a Four-Die Forging Device (FDFD) design solution depends upon each particular production case. In order to obtain the best results from using the FDFD, it is necessary in each case to get detailed information about the existing forging technology and the press. Based on this data an optimal FDFD design solution and forging technologies are proposed.

So far, more than 20 FDFDs have been built and installed on forging presses and radial-forging machines at primary metal producing companies in Ukraine, Russia, China, Spain, Germany, Italy and Brazil. Based on accumulated experience and investing into $R \& D$ activities the authors of this paper continuously work at further improvements of the FDFD design, develop new solutions for particular production applications and respective forging technologies. All this streamlining activity is aimed to reduce the customer forging costs and eliminate non-operational wastes.

\section{References}

[1] V. A. Lazorkin, Method of forged parts production, Patent of Ukraine (No. 98409, B21 J 1/04, 5/00. 2011)

[2] Viktor Lazorkin, Yuriy Melnykov. New Technologies of Forging of Ingots and Blanks by Four Dies in Open - Die Forging Presses. Proc. 18th IFM 2011, Sept. 12 - 15, Pittsburgh, USA, p. 326-332

[3] Gonzales J. R., David P. F., Gordon J., Llanos J. M. FEM Simulation of the New Radial Forging Device Process at Sidenor. Proc. 17th IFM 2008, November. 3-7, Santander, Spain, p. 237-243 
[4] V. Lazorkin, Four-peen forging device for forging presses, European Patent (No. 2540411 B1 dd. 17.08.2016)

[5] V. Lazorkin, Four-peen forging device for forging presses, US Patent (No. 9,283,614 B2, B21 J13/02, B21 J9/02, B21 J7/14, 2013)

[6] Viktor Lazorkin, Dmitriy Lazorkin, New Development of Four-Die Forging on Open-Die Forging Presses, Proceedings, $19^{\text {th }}$ International Forgemasters Meeting, Tokyo Bay Area, Japan (2014), p. 210-214

[7] Roberto Tiburcio C. Frota Junior, Gustavo Acarine De Campos, Paulo Augusto Morais De Oliveira, Gerson
Graciano. Comparison between four die forging device and conventional forging processes of cold work tool steel. Proc. $20^{\text {th }}$ IFM 2017, Sept. 15-19, Congress Graz, Austria, p. 545553

[8] V. A. Lazorkin, V. V. Nikitin, Four-die forging device, Patent of Ukraine (No. 102329, B21 J 13/08, 7/16. 2014)

[9] V. A. Lazorkin, V. V. Nikitin, Four-die forging device, Patent of Ukraine (No. 101909, B21 J 13/08, 7/16. 2013)

[10] Viktor Lazorkin, Dmitriy Lazorkin, Four-die forging devices in primary metal production, Kovarenstvi (2015, Volume 55), p. $26-30$ 